ORIGINAL ARTICLE

\title{
Perinatal pathology in the context of a clinical trial: attitudes of bereaved parents
}

\author{
C Snowdon, D R Elbourne, J Garcia
}

Arch Dis Child Fetal Neonatal Ed 2004;89:F208-F211. doi: 10.1136/adc.2003.041392

See end of article for authors' affiliations .....................

Correspondence to: C Snowdon, Centre for Family Research, University of Cambridge, Free School Lane Cambridge CB2 3RF, UK cms1000@cam.ac.uk

Accepted 5 October 2003
Background: Interviews with neonatologists in a related study had revealed a degree of discomfort with approaching bereaved parents for postmortem examinations (PMs) and a widespread concern that parents should not be further distressed or feel under pressure to consent.

Objective: To report the attitudes of bereaved parents to trial related perinatal PMs, in the light of declining perinatal PM rates and poor levels of participation in pathology studies.

Methods: A qualitative study was carried out, using semistructured interviews. The study involved 11 interviews with 18 bereaved parents from five UK neonatal units. The parents had consented to the enrolment of their baby in one of two neonatal trials.

Results: The data provide support for the careful approach described by neonatologists in a related study, but also suggest that it may be possible to approach more parents without undermining their wellbeing. The interviews show the variety of reactions to PMs that one would expect, from parents who were clear that they did not want a PM to others who felt that they needed the information from the examination. Between these extremes were parents who were initially discomforted by the idea but who then made the decision to go ahead. Parents who elected to have a PM did so for their own needs, or to contribute to a trial, or for both reasons. The fact that the subject was raised was generally not seen as inappropriate, and none stated that they felt that they were actually pressured into making their decision. The data also suggest that for some parents the degree of caution and selectivity exercised by the neonatologists may not be entirely appropriate. In two cases, consent for the PM was driven by a sense of making an altruistic contribution to research, and, in another two, altruism was expressed in the context of their own desire for information from a PM.

Conclusions: It is important to determine whether trial related pathology studies are considered by professionals and lay people to be worth while and feasible. If there is support for such studies, the challenge is to develop the means to approach more parents in the most sensitive way. l: a review of the literature ${ }^{1}$ and through a qualitative study of the views of pathologists and neonatologists, ${ }^{2}$ we have examined issues raised by neonatal postmortem examinations (PMs) conducted for research purposes. We conclude that little is known about the impact on parents of requesting a PM on an infant who has been enrolled in a clinical trial. Although there is some evidence that contributing to research is important to some parents ${ }^{3}$ and to other bereaved relatives, ${ }^{45}$ the effect of the request to make such a contribution has not previously been explored.

Our research with professionals showed that some neonatologists were uncomfortable about approaching bereaved parents for PMs because of their concern that parents should not be further distressed or feel under pressure to consent. Others have shown that families can experience distress if communication is poor ${ }^{5}$ or may be less likely to agree to a PM if an approach is perceived as insensitive. ${ }^{6}$ Two important obstacles that also emergedthat is, devaluation of PMs among younger staff, and the feeling that PMs may be unnecessary in certain cases (known cause of death, prematurity) - have also been highlighted in the wider literature. ${ }^{467} \mathrm{~A}$ most important factor that has not previously been described was a sense of disconnection between trial interventions and pathology studies.

We wished to learn whether the concerns expressed by the neonatologists are reflected in the parental accounts. We used the opportunities afforded by a related study to explore parents' views.

\section{METHODS}

The research was carried out with bereaved parents of babies who were enrolled in one of two neonatal trials at one of five centres. The trials were the INNOVO trial (which compared giving inhaled nitric oxide to babies with severe respiratory failure with the usual ventilatory care (www.innovo-trial. org.uk)) and the CANDA trial (which compared two surfactants for preterm babies). ${ }^{8}$ The professionals interviewed in the linked study ${ }^{2}$ were associated with the same two trials. Approval was obtained from all relevant ethics committees.

Almost half of the babies recruited to the INNOVO trial died, and there was a low PM rate. In the trial, 80/168 babies died and 27 PMs were carried out (34\%). More PMs were carried out for term than for preterm babies (67\% v 26\%). In the INNOVO centres linked to this qualitative study, $48 / 84$ babies died and 16 (33\%) PMs were carried out. For the CANDA trial nearly a quarter of the babies died (45/199) and 17 underwent a PM $(45 \%)$. In the CANDA centres in the qualitative study, 38/159 died and 16 underwent a PM (42\%).

Contact with the parents was negotiated by the local hospital consultant, who would approach them either at a bereavement visit or by letter or telephone to ask if the researcher could write to them about the qualitative study. Access to bereaved parents in fact proved to be very difficult. Permission to approach parents was withheld at one of the largest study centres, and many cases in which consultants had concerns over parental wellbeing were excluded.

Twenty one letters were sent to parents ( 16 INNOVO and 5 CANDA). No reminder letters were sent, at the request of the research ethics committees. Eleven interviews were carried 
out, by CS (8), MM (2), and DE (1). The interviews took place in the parental home and were tape recorded and fully transcribed, with the exception of one, which was corrupted. The loss of data from this one tape left 10 interviews (seven INNOVO and three CANDA) with 16 parents of 12 babies who had died. The transcripts were analysed by identifying and grouping emerging themes until no new issues were raised. This process was assisted by a textual analysis computer package, Atlas-ti. ${ }^{9}$ One of us, CS, was primarily responsible for the analysis, but DE and JG also read all the transcripts and agreed the analysis.

\section{VIEWS OF THE BEREAVED PARENTS}

In four cases, the parents had decided that they did not want any further examinations for their babies. In five cases, the parents agreed to a PM. The information is not available for two cases.

Themes that emerged from the interviews included the parents' reactions to the offer of a PM (in particular whether or not they felt pressured in the discussion), whether they articulated any sense of connection between the trial and a $\mathrm{PM}$, and the value attached to the information derived.

\section{Reaction to the offer of a PM}

There were no particularly negative accounts from the parents of their discussions with neonatologists. There was only one case in which parents specifically stated that they refused because of the organ retention controversies. ${ }^{12}$

A mother of twins enrolled in the INNOVO trial described a feeling of pressure. She felt it was thought to be clear why her babies had died, but that there was some doubt about one particular aspect of their case. They were left to think the issue over, and their doctor telephoned them at home for their decision. The mother reported that he specifically said that he did not wish to pressure them, but she commented:

I must admit I didn't feel comfortable saying no to him. I remember thinking at the time that $-I$ don't know if it was his manner-but I just felt like a postmortem would be more for him than it would be for us, and I just wasn't prepared to do it.

She found the idea of a PM very difficult, even though there was the possibility that it would provide them with useful information. She told her partner "I just can't", on the grounds that their babies were "like dolls".

The desire not to pressurise can result in very limited discussions, leaving parents feeling that PMs are irrelevant in their case. One father stated that during their discussion of the possibility of a PM, there was no mention of previous participation in the INNOVO trial, and that in fact they were encouraged to view a PM as unnecessary by their consultant.

[A postmortem] was brought up as an option and I think [the doctor], without wishing to put words in our mouths said, you know as far as they could see [he] was born premature and there was nothing really wrong with him ... Maybe he was hinting that they wouldn't actually find anything out that they didn't really already know and really that [was] coupled with the fact [that] he'd had more than enough done to him.

These parents felt that they were being spared the stress of deciding about a PM. They said that they appreciated being guided by a caring neonatologist who had eased the situation for them. The mother commented that they "didn't feel pressured at all either way."

\section{Connection to the trial}

Four of the couples had made a connection between the trial and a PM. One couple sought out a PM, raising the subject with their doctor. This was part of a strong desire to understand their baby's death and to make sense of events. They wanted to know whether inclusion in the trial could have contributed to the death, and felt that the results were reassuring. The generation of valuable information from a PM was an important coping strategy for both parents.

It's getting the positive from the negative because a baby's death becomes a very negative thing. ... When it's a prem baby, they don't make a noise, they don't open their eyes, so you never see the colour of their eyes. The only thing you've got is that touch... The only events that you remember are painful events so that's why ... you have to start getting positives. And the positive for us was that, number one we may have got an answer, but number two somebody else may gain from that.

Another couple whose baby was enrolled in the INNOVO trial also articulated altruistic feelings, specifically in terms of the trial. The mother had initially felt very uncomfortable with a PM, whereas her partner was prepared to go ahead. She changed her mind as she came to feel that there would be certain benefits from the information, in clarifying the cause of death for themselves, and as a contribution for others.

[We] agreed ... because even though it [nitric oxide] didn't work for us, if they could get anything from it that would help other people then it was worth it ...

The father explained how they came to view the PM.

[We felt that] he's had this trial and they might as well get what information they can about it. You know at least he hadn't gone to waste then.

Parents of two babies appeared to have consented to a PM on purely altruistic grounds. One mother consented and said in the interview, "if it'll help somebody else later on then I'm fine." Her partner, however, subsequently refused, and the PM did not take place. Another mother of a baby enrolled in the INNOVO trial specifically discussed the value of a PM for research purposes. Although her initial reaction was to refuse, after a further discussion with her baby's consultant in which she was told that the examination would be useful for research purposes, she agreed. She stated that she did not feel under pressure.

[He] asked if they could do an autopsy and I said no, and then he says "well she's been on a trial and it would help". I says "well if it's going to help another baby ... yeah, you can do it". He says 'we're just going to take part of her lung away, just to see what it was" and I said "Okay then."

Thereafter her story involves the type of experiences which can, understandably, make neonatologists nervous of approaching parents. She had wanted to bring her baby home before the funeral but had a five day delay because of the PM. After three days she called her doctor, saying "I'm [doing] this as a favour to you, but I want her home". When the baby was returned to her she was distressed when she 
examined her baby's body, as she had not expected to see an incision in the head.

I'd dressed her [in a] little dress and a hat [but] they put her hat on back to front, the wrong way so I took [it] off and they'd gone into her head and I didn't know. And it was just horrible. ... I'm annoyed that they didn't say that they were going to go in. I didn't know you know and I did say to [the doctor] when I went back in, ... "when you say they're gonna have an autopsy, I think you should tell them that you're going to go into their head", I says "because that has stayed with me and that's a sight that will never ever leave me".

Clearly she was unprepared for such a disturbing sight, and for her there was a sense that something quite inexplicable had happened. She could see no reason why it would have been necessary to have carried out an examination of the brain. Whether or not she was told at the time that she gave her consent of the various elements of the PM cannot be determined. What is clear is that she did not feel that she had been told of this detail and was subsequently confronted with the reality of a PM in a shocking and brutal way. She was asked in the interview if it might have helped to have written information about what was going to happen, and she felt that it would. Despite this experience, she spoke very positively of the doctor involved, saying "I got on really well with him"

\section{DISCUSSION}

It has been argued that, in a context of stress, desperation, and vulnerability, parents of babies in neonatal care will give consent "to do almost anything to their baby", ${ }^{10}$ and that consent in certain neonatal trial settings is "an elaborate ritual"11 or "a sham". ${ }^{12}$ There is also empirical evidence that neonatal trials may have higher rates of consent than trials in other settings: Campbell et $a l^{13}$ found that, in a sample of trials, $96 \%$ of neonatal trials reported $100 \%$ consent rates, compared with $68 \%$ of general paediatric trials. Whereas few decline to participate in neonatal trials, the numbers agreeing to trial related PMs for neonates are, in contrast, very low.

The two consent encounters are in theory linked, taking place at different points in a linear process and involving the same parties. The circumstances are, however, clearly different and in practice have become rather disconnected. At consent for recruitment to a trial, the fact that the offer of enrolment is often in the context of trying to save the life or improve the condition of a very sick baby is likely to motivate professionals to offer enrolment and parents to consent. At the second point, the death of the baby is uppermost in the minds of all concerned, and there is nothing more that can be done to benefit that child. The sense of striving for a solution is replaced by the need to deal with the emotional sequelae of bereavement, and any further requests can be seen as inappropriate. In cases when parents are grief stricken or even angry, engagement with discussion of the benefits of PMs for others is highly unlikely. This broad division of circumstances can mean that, as shown by our study of the views of neonatologists, ${ }^{2}$ doctors who are willing to recruit to trials can be reluctant to go on to recruit into trial related pathology studies, for fear of making seemingly inappropriate and insensitive requests.

The data from this small study of the views of bereaved parents provide support for this careful approach, but also suggest that it may be possible to approach more parents without undermining their wellbeing. The parents who were interviewed show the variety of reactions to PMs that one would expect, from those who were clear that they did not want a PM to others who felt that they needed the information from the examination. Between these extremes were parents who were initially discomforted by the idea but who then made the decision to go ahead. Parents who elected to have a PM did so for their own needs, or to contribute to a trial, or for both reasons. It is reassuring that the fact that the subject was raised was generally not seen as inappropriate, and none stated that they felt that they were actually pressured into making their decision.

The data also suggest that, for some parents, the degree of caution and selectivity exercised by the neonatologists may not be entirely appropriate. In two cases, consent for the PM was driven by a sense of making an altruistic contribution to research, and, in another two, altruism was expressed in the context of their own desire for information from a PM. Although these parents are not necessarily typical, their views may be shared, but in a more private way, by other parents who are not always given the option of a PM. If bereaved parents are not given information about the value of PM samples, even those from a limited PM, ${ }^{14}$ they may be denied the chance to make their own decisions about contributing to research. This type of research may in fact be appreciated by some parents who have been deeply affected by neonatal loss. ${ }^{15}$ From our interviews with many parents who have been involved in neonatal trials, ${ }^{16-18}$ it seems that neonatal research is often highly valued. They can be keen to make some contribution and often express this when interviewed. Whether or not this can be said to extend to the larger group of bereaved parents, and would be applied to pathology studies, cannot as yet be answered. It would seem, however, that there is evidence in the literature ${ }^{3419}$ and in our small study, that some may support the idea of contributing to research through a PM. The specific context of a trial may make their contribution more concrete than an abstract notion that a PM may contribute to knowledge in some general way. We would suggest, although it is conjecture, that a positive sense that babies of the future may benefit from this decision may be important to such parents in the longer term. Undoubtedly, however, there are parents who would find the request very difficult. The difficulty for neonatologists is working out who will be receptive and who will be disturbed, a minefield they tread with understandable caution.

\section{Conclusions}

It is important that the trials community explores this issue further to determine whether or not trial related pathology studies are considered by professionals and by lay people to be worth while and feasible. If there is support for such studies, the challenge is to develop the means to approach more parents in the most sensitive way.

There are important limitations to this very small study. PMs for trial purposes were not the focus of the interviews. As the data are incidental they do not provide a full description of experiences of and reactions to the consent process. We would suggest that a larger study dedicated to researching the issues raised here is appropriate and timely. The practical and methodological problems associated with such a study should not be underestimated. Access to bereaved parents is difficult, as clinicians and ethics committees wish to protect the families under their jurisdiction. Access here was negotiated by consultants, and it is likely that this acts as a filter. Consultants were very protective and were less likely to allow those who had been particularly distressed to be approached about participation in research that would explore their distressing experiences. Inevitably, interviews do raise some difficulties for parents in drawing on a traumatic time, but we found the parents to be thoughtful and often keen to be heard. They constitute a 
group with a considerable personal investment in developments in neonatal intensive care. Their opinions should be sought on the best ways to protect parents with similar experiences to their own.

\section{ACKNOWLEDGEMENTS}

We thank the parents who gave generously of their time. The Nuffield Foundation funded this study. JG worked on this study at the National Perinatal Epidemiology Unit where she was funded by the Department of Health. CS was accommodated by CFR and assisted by Sally Roberts. Project coordination was facilitated by senior staff at the centres involved. Marion MacAllister conducted two of the interviews, and Nina Hallowell, John Allison, and David Field (and other members of the project's advisory group) commented on drafts of the paper.

\section{Authors' affiliations}

C Snowdon, D R Elbourne, J Garcia, Medical Statistics Unit, London School of Hygiene and Tropical Medicine, University of London, Keppel Street, London WCIE 7HT, UK

C Snowdon, Centre for Family Research, University of Cambridge, Free School Lane, Cambridge CB2 3RF, UK

\section{REFERENCES}

1 Snowdon C, Elbourne DR, Garcia J. Perinatal pathology in the context of a clinical trial: a review of the literature. Arch Dis Child Fetal Neonatal Ed 2004;89:F200-3.

2 Snowdon C, Elbourne DR, Garcia J. Perinatal pathology in the context of a clinical trial: attitudes of neonatologists and pathologists. Arch Dis Child Fetal Neonatal Ed 2004;89:F204-7.
3 Rankin J, Wright $C$, Lind T. Cross sectional survey of parents' experience and views of the postmortem examination. BMJ 2002;324:816-18.

$4 \mathrm{McPhee}$ SJ, Bottles K, Lo B, et al. To redeem them from death. Reactions of family members to autopsy. Am J Med 1986;80:664-71.

5 Start RD, Sherwood SJ, Kent G, et al. Audit study of next of kin's satisfaction with clinical necropsy service. BMJ 1996;312:1516.

6 VanMarter LJ, Taylor F, Epstein MF. Parental and physician-related determinants of consent for neonatal autopsy. Am J Dis Child 1987;141:149-53.

7 Cottreau C, Mclntyre L, Favara BE. Professional attitudes towards the autopsy. A survey of clinicians and pathologists. Am J Clin Pathol 1989;92:673-6.

8 Ainsworth SB, Beresford MW, Milligan DWA, et al. Pumactant and poractant alfa for treatment of respiratory distress syndrome in neonates born at 2529 weeks' gestation: a randomised trial. Lancet 2000;355:1387-92.

9 Muhr T. A prototype for the support of text interpretation. In: Tesch R, ed. Qualitative sociology. New York: Human Science Press, 1991.

10 McIntosh N. Strengthen ethical committee's role [letter]. BMJ 1993;307:1496.

11 Mason S. Obtaining informed consent for neonatal randomised controlled trials: an "elaborate ritual"? Arch Dis Child Fetal Neonatal Ed 1997;76:F143-5.

12 Anon. Your baby is in a trial [editorial]. Lancet 1995;345:805-6.

13 Campbell H, Surry SAM, Royle EM. A review of randomised controlled trials published in Archives of Disease in Childhood from 1982-96. Arch Dis Child 1998;79:192-7.

14 Raffles A, Ropel C. Non-invasive investigations are also helpful if permission for a necropsy is refused. BMJ 1995 April 1;310:870.

15 Chiswick $M$. Perinatal and infant postmortem examination. $B M$ 1995;310:141-2.

16 Snowdon C, Garcia J, Elbourne D. Making sense of randomization: responses of parents of critically ill babies to random allocation of treatment in a clinical trial. Soc Sci Med 1997:45:1337-55.

17 Snowdon C Garcia J, Elbourne D. Reactions of participants to the results of a randomized controlled trial: an exploratory study. BMJ 1998;317:21-6.

18 Snowdon C, Elbourne D, Garcia J. Zelen randomization: attitudes of parents participating in a neonatal clinical trial. Control Clin Trials 1999:20:149-71.

19 Sirkia K, Saarinen-Pihkala UM, Hovi L, et al. Autopsy in children with cancer who die while in terminal care. Med Pediatr Oncol 1998;30:285-9. 